\title{
COMPETITIVIDADE BASEADA NO MARKETING ECOLÓGICO
}

\author{
Sérgio Luís Stirbolov Motta'
}

\section{Resumo}

A dependência de energia, o desperdício de água, o mau uso e manejo de florestas, obras irresponsáveis ambientalmente, poluição de mananciais, mares, oceanos, terra, ar, e inúmeras outras ações que prejudicam o meio ambiente vêm causando dificuldades à própria sociedade que ainda as admitem, embora havendo crescentes restrições. Os impactos negativos tomaram tamanha dimensão que grupos organizados como o Greenpeace e o SOS Mata Atlântica vêm ganhando cada vez mais projeção e cumprindo um papel fundamental na conscientização da população, contribuindo, também, para que ações empresariais irresponsáveis ambientalmente sejam pressionadas pela sociedade. O objetivo deste artigo é apresentar a incorporação da responsabilidade ambiental às empresas como um diferencial capaz de, por um lado, contribuir para a efetiva melhoria da qualidade de vida dos cidadãos e, por outro, constituir-se em vantagem competitiva. Para tanto, é apresentada uma breve discussão acerca da vantagem competitiva e do marketing ecológico, e os resultados de uma pesquisa qualitativa, realizada em 1999 pelo autor, que teve por objetivo conhecer a importância do "fator meio ambiente" nas decisões de compra de consumidoras de determinadas categorias de produtos, com o intuito de se averiguar a predisposição em relação a produtos ecologicamente corretos.

Palavras-chave: Competitividade. Marketing Ecológico. Responsabilidade Social Empresarial.

\section{INTRODUÇÃO}

A busca por melhor conveniência e qualidade de vida fez com que ações inadmissíveis em termos de sustentabilidade ambiental fossem e continuem sendo praticadas por empresas.

' Mestre Administração de Empresas pela Universidade Presbiteriana Mackenzie. Professor e pesquisador da Universidade Presbiteriana Mackenzie e professor da Pontifícia Universidade Católica de São Paulo (PUCSP). Rua Rodrigo Vieira, 544 - V. Mariana - São Paulo - SP - Cep 04 I I5-060. E-mail: smotta@mackenzie.br. Artigo recebido em: 30/I 0/2006. Aceito em: 04/03/2008. Membro do Corpo Editorial Científico responsável pelo processo editorial: Miguel Pina e Cunha. 
A dependência de energia, o desperdício de água, o mau uso e manejo de florestas, obras irresponsáveis ambientalmente, poluição de mananciais, mares, oceanos, terra, ar, e inúmeras outras ações que prejudicam o meio ambiente vêm causando dificuldades à própria sociedade que ainda as admitem, embora havendo crescentes restrições.

Os impactos negativos tomaram tamanha dimensão que grupos organizados como o Greenpeace e o SOS Mata Atlântica vêm ganhando cada vez mais projeção e cumprindo um papel fundamental na conscientização da população, contribuindo, também, para que ações empresariais irresponsáveis ambientalmente sejam pressionadas pela sociedade.

Se, por um lado, a pressão da sociedade impele as organizações de buscarem alternativas ecologicamente corretas para desempenharem as suas atividades, por outro, o comodismo, o imediatismo, as dificuldades e os custos associados às mudanças necessárias colocam-se como barreiras à sua implementação.

Porém, dada a intensidade da competição entre as empresas nos mais diversos setores de atividade, a gestão ambiental responsável pode ser uma maneira de criar e de desenvolver diferenciais em relação à concorrência.

O objetivo deste artigo é apresentar a incorporação da responsabilidade ambiental às empresas como um diferencial capaz de, por um lado, contribuir para a efetiva melhoria da qualidade de vida dos cidadãos e, por outro, constituir-se em vantagem competitiva.

Para tanto, é apresentada uma breve discussão acerca da vantagem competitiva e do marketing ecológico, e os resultados de uma pesquisa qualitativa, realizada em 1999 pelo primeiro autor, que teve por objetivo conhecer a importância do "fator meio ambiente" nas decisões de compra de consumidoras de determinadas categorias de produtos, com o intuito de se averiguar a predisposição em relação a produtos ecologicamente corretos.

\section{COMPETIÇÃO E VANTAGEM COMPETITIVA}

A competição entre as organizações existe basicamente porque um ou mais "player" - atual ou potencial - de um determinado setor econômico percebe a oportunidade de melhorar sua posição (ou estabelecê-la), ou sente-se pressionado por outro "player".

Isso ocorre porque os movimentos de uma empresa repercutem nas demais, existindo uma relação de interdependência. Dessa forma, é constante a busca por alternativas que permitam às organizações sobrepujar as ações dos seus concorrentes, uma vez que se não o fizerem, acabarão por receberem impactos das ações deles, o que pode ser prejudicial e criar situações difíceis de serem revertidas. 
Nesse contexto, as empresas buscam criar, desenvolver e sustentar vantagens em relação às suas concorrentes, de forma que lhes permita crescer e se desenvolver em ambiente competitivo.

O termo vantagem competitiva, amplamente divulgado por Michael Porter no início dos anos 80, diz respeito justamente aos diferenciais que uma organização deve criar e sustentar em relação aos seus concorrentes, como forma de contribuir para a sua lucratividade e o seu desenvolvimento. O referido autor apontou, então, três direcionamentos estratégicos que as empresas poderiam adotar com vistas a obtê-la: liderança em custo, diferenciação, ou foco - este combinado com custo ou diferenciação (PORTER, 1986).

A liderança em custo é adotada pela empresa que deseja ser o produtor de mais baixo custo em sua indústria, obtido através de, por exemplo, economia de escala, tecnologia patenteada, acesso preferencial a matérias-primas, entre outros. Geralmente comercializa um produto padrão, que não tem capacidade de exceder a expectativa do consumidor, porém é interessante por conta de seu baixo preço. Porter (1986) lembra que desenvolver um produto padrão não significa que as necessidades dos consumidores não devem ser levadas em conta; em outras palavras, é necessário que o produto apresente ao menos um nível de diferenciação que seja capaz de equiparálo aos principais concorrentes.

A estratégia de diferenciação conduz a empresa a tentar obter vantagem através de ofertas altamente valorizadas pelos consumidores, mesmo que mais custosas. $\mathrm{O}$ custo maior não é problema porque os consumidores permitem-se pagar um preçoprêmio por produtos que são percebidos como mais capazes de satisfazerem suas necessidades, o que não significa que se possa descuidar de sua estrutura de custos, pois isso comprometeria os resultados da empresa. Marketing é a principal forma de obtenção de vantagem competitiva através da diferenciação.

Se a estratégia genérica escolhida pela empresa é o foco, ela deve escolher um segmento de mercado em que atuar é desistir de atender a outros segmentos ou à indústria como um todo. A partir da escolha do segmento, ela deve combinar a estratégia de foco com liderança em custo ou diferenciação para obter vantagem competitiva.

Muito embora o mesmo autor apresente as três "estratégias genéricas" com o intuito de guiar as ações empresariais a fim de se criar uma posição defensável a longo prazo, o aumento da competitividade, em razão da maior acessibilidade a bens, know how e capital, fez com que os direcionamentos estratégicos propostos passassem a ser questionados, sobretudo em termos de operacionalização e de sustentabilidade. Ressalta-se que o próprio autor apontou, naquela ocasião, dois riscos inerentes à sua proposta: o primeiro, não conseguir criar ou sustentar a estratégia escolhida; e, o segundo, que os benefícios advindos da estratégia escolhida fossem desgastados com a evolução do setor (PORTER, 1986, p. 58). 
Em vista da nova realidade competitiva, D’Aveni (1995) introduziu o conceito de hipercompetição, que diz respeito a uma evolução da abordagem estática dada até então à estratégia competitiva. Na sua visão, a competição baseada em estratégias que proporcionavam resultados satisfatórios em ambientes mais estáveis deixara de ser adequada num contexto de hipercompetição.

De acordo com D’Aveni (1995), a abordagem estática da estratégia considera quatro arenas de competição: custo e qualidade, timing e know-how, fortalezas e reservas financeiras. Para o autor, "os modelos estáticos de estratégia descrevem a competição em um determinado momento” (D’AVENI, 1995, p. XXXVIII).

Segundo D’Aveni (1995, p. LII), "na hipercompetição o sucesso depende do desenvolvimento de uma série de novas vantagens que rompam (não sustentem) o status quo e que ajam junto a outras empresas, tentando perturbar esse status quo". Essa abordagem "dinâmica" considera que toda e qualquer vantagem que se possa criar é temporária.

De acordo com o autor, a única barreira de entrada sustentável é o comportamento hipercompetitivo das empresas, pois toda vantagem é erodida, uma vez que seus benefícios duram até pouco depois de os concorrentes começarem a copiá-la. Assim, afirma que a sustentação de vantagens pode ser um equívoco, e que se deve sempre buscar a ruptura, criando-se uma série de vantagens temporárias (D’AVENI, 1995).

As empresas hipercompetitivas devem buscar manter-se à frente dos seus concorrentes e neutralizar os seus esforços em suplantá-las, de forma a evitar a concorrência perfeita já que esta, por limitar o lucro, é destrutiva do ponto de vista empresarial.

\section{RESPONSABILIDADE SOCIAL E MARKETING ECOLÓGICO}

Não obstante o termo marketing ser bastante difundido nos dias atuais, é pouco compreendido. Pior que isso, é utilizado como sinônimo de ludibriagem ou de safadeza: a empresa que engana o consumidor "faz marketing", lança produtos que não cumprem com as promessas apresentadas na hora da venda; o profissional antiético, que engana o próximo, é "marqueteiro" (aliás a própria denominação "marqueteiro" é por si só pejorativa).

A teoria mercadológica prega exatamente o contrário. A empresa que engana o consumidor ou qualquer um de seus parceiros comerciais pode estar fazendo qualquer coisa, menos marketing.

Marketing, conceitualmente, ocorre quando a empresa tenta obter lucro a partir da satisfação das necessidades e dos desejos de seus consumidores (GRACIOSO, s.d.; RICHERS, 1994; COBRA, 1997; SEMENIK; BAMOSSY, 1995; SANDHUSEN, 2000; LAS CASAS, 1997; MCCARTHY; PERREAULT, 1997; ROCHA; CHRISTENSEN, 1999; KOTLER, 2000; CHURCHILL, JR.; PETER, 2000). Não 
deve haver meio termo; se a empresa tem por filosofia de negócio obter lucro dessa forma, ela pratica marketing em sua plenitude; se não, não pratica marketing.

A má interpretação vem da confusão entre os conceitos de "venda" e de "marketing". A empresa orientada para a "venda" parte de um produto pré-estabelecido e tenta convencer os consumidores a comprá-lo; essa tentativa envolve decisões típicas de marketing, como política agressiva de preços, promoções de vendas, agregação de valor ao produto, capacitação da força de vendas, propaganda, entre outras. A empresa orientada para marketing primeiro pergunta aos consumidores o que eles necessitam e depois toma suas decisões baseada na satisfação destas necessidades; é menos uma técnica e mais uma filosofia empresarial.

Contribui também para a má interpretação do conceito de marketing a redução de suas atividades à de propaganda. Propaganda (ao lado de promoção de vendas, relações públicas e merchandising, por exemplo) é uma das ferramentas que a empresa utiliza para se comunicar com o mercado e é um dos elementos do composto de marketing, conjunto de variáveis que a mercadologia controla para poder obter lucro satisfazendo necessidades e desejos de consumidores, teoria criada por McCarthy (1960). Os outros elementos do composto são produto, preço e distribuição, e somente a conjunção desses quatro elementos permite à empresa a orientação ao mercado. Silva (1997) argumenta que ao se preocupar exclusivamente com propaganda, o profissional de marketing foca suas decisões apenas no "periférico", na "aparência", deixando de lado o central e o essencial, o que, neste caso, afasta as decisões empresariais do conceito central de marketing.

Como o objetivo central do marketing é satisfazer os consumidores, presumese que, se isso ocorrer, o relacionamento comercial entre esses consumidores e a empresa que lhes oferece algo ocorra por muito tempo, a longo prazo, o que é uma garantia de faturamento e (se a empresa for bem administrada) de lucro. De acordo com Levitt (s.d.), manter e conservar o cliente é atribuição do marketing, o que presumivelmente é decorrência de sua satisfação.

No entanto, para que isso ocorra (em outras palavras, para que a filosofia de marketing se prolifere pela empresa), é necessário que todos dentro da organização entendam que suas funções existem para que o consumidor seja atendido. É o que Kotler (2000) chama de "marketing integrado": todas as funções de marketing coordenadas e todos os colaboradores (desde o diretor-presidente até o nível hierárquico mais baixo) e departamentos da empresa imbuídos da necessidade de satisfazer o consumidor.

Uma crítica pertinente que se faz atualmente à atividade de marketing é que, satisfazendo as necessidades e desejos de públicos-alvo variados, multiplica o consumo das ofertas (produtos) concebidas para a satisfação dessas necessidades, o que não coaduna com alguns problemas sociais, demográficos e ambientais que se vivencia hoje. 
Em outras palavras, as empresas podem perfeitamente ser orientadas pelo mercado, estabelecendo trocas com os consumidores que resultam na satisfação de suas necessidades e desejos, mas, de alguma forma, não contribuindo para seu bem-estar a longo prazo, tampouco para a qualidade de vida da sociedade como um todo.

Face a essa nova conjuntura, Kotler (2000, p. 47) sugere a adoção do que denomina "marketing societal", o que, em sua definição determina "as necessidades, os desejos e os interesses dos mercados-alvo" e fornece "as satisfações desejadas mais eficaz e eficientemente do que a concorrência, de uma maneira que preserve ou melhore o bem-estar do consumidor e da sociedade."

Marketing societal refere-se à incorporação de considerações relativas aos problemas sociais em estratégias de marketing desenvolvidas e implementadas com vistas a aumentar a aceitabilidade de produtos (EL-ANSARY, 1974, p. 317). A incorporação da responsabilidade social nas estratégias de marketing é decorrente da sua evolução, com vistas a oferecer valor aos públicos-alvo, de forma que sejam estimulados. Assim, esclarece o autor, fica claro que o marketing societal pode ser utilizado por qualquer organização (EL-ANSARY, 1974, p. 317).

Na verdade, este componente "societal" (ou societário) do marketing foi inicialmente estudado no final da década de 60 do século passado, pela então intitulada Escola do Macromarketing ("The Macromarketing School"), que inseria as variáveis exógenas às organizações na teoria de marketing e que tinha como um de seus pressupostos o fato de que o marketing é uma atividade social que é influenciada e influencia a sociedade (SHETH; GARDNER, 1984).

É nesse contexto do marketing societal, da responsabilidade social das organizações e do desenvolvimento sustentável que se revela o marketing ecológico. $\mathrm{Na}$ definição de Santesmases (1996 apud CALOMARDE, 2000, p. 22):

\begin{abstract}
O marketing ecológico é um modo de conceber e executar a relação de troca, com a finalidade de que seja satisfatória para as partes que nela intervêm, a sociedade e o meio ambiente, mediante o desenvolvimento, valoração, distribuição e promoção por uma das partes de bens, serviços ou idéias que a outra parte necessita, de forma que, ajudando a conservação e melhora do meio ambiente, contribuem ao desenvolvimento sustentável da economia e da sociedade.
\end{abstract}

Deve ficar claro que para que o marketing ecológico seja implantado pelas empresas é necessário que nela esteja presente uma macro-orientação, em nível estratégico, de respeito ao meio ambiente e à sociedade (MILES; MUNILLA, 1995), em total conformação com os conceitos anteriormente explanados de marketing societal.

As ferramentas que o marketing tradicional utiliza para satisfazer as necessidades e desejos dos consumidores e contribuir com os objetivos organizacionais (o composto de marketing) são as mesmas utilizadas pelo marketing ecológico. O que muda, neste 
último, é o espectro de tomada de decisão, que agora contempla não só os consumidores potenciais e atuais das ofertas da empresa, mas também, e em igual magnitude, o respeito à sociedade como um todo por meio da preservação do meio ambiente.

Deve ficar evidente, também, que a adoção do respeito ao meio ambiente pela atividade de marketing em momento algum deve ser confundido com uma mudança ideológica da prática empresarial. Todo o movimento de marketing ambiental, bem como todas as outras ações empresariais relacionadas à gestão ambiental, são desenvolvidos dentro do que Layrargues (1998, p. 44) titula de "racionalidade econômica", em que "o reducionismo econômico da lei da oferta e procura ainda é o imperativo determinante do controle das decisões humanas".

De acordo com Kinlaw (1998, p. XV), "as empresas devem se tornar ambientalmente responsáveis, ou 'verdes', para sobreviver'. Para o autor, pouco adianta as empresas oferecerem produtos e serviços que não levem em consideração o meio ambiente, uma vez que a questão ambiental tem evoluído ao ponto de agentes sociais pressionarem por ações ambientalmente responsáveis (KINLAW, 1998, p. XV).

Note-se que ser ecologicamente correta não deve implicar inviabilização dos negócios. Ao contrário, deve contribuir para a criação e o desenvolvimento de diferenciais que permitam obter benefícios.

Kinlaw (1998, p. XXI) elucida a importância da questão ambiental para as empresas ao fazer as seguintes afirmações:

- Quanto mais cedo as organizações enxergarem a questão ambiental como uma oportunidade competitiva, maior será a sua probabilidade de sobreviver e lucrar; e

- É pela ênfase da questão ambiental como uma oportunidade de lucro que poderemos controlar melhor os prejuízos que temos causado ao meio ambiente.

Kinlaw (1998, p. 46-48) apresenta uma série de fatores que pressionam as empresas a buscarem a realização de ações ecologicamente adequadas, que vão desde leis específicas até a concorrência e as preferências do consumidor. Assim, nota-se que claramente se trata de um processo irreversível.

Além disso, o conhecimento por parte dos consumidores, de que o consumo de determinados produtos e serviços geram benefícios, ou mesmo a redução de malefícios, à sociedade como um todo deve contribuir para a sua satisfação.

\section{METODOLOGIA DA PESQUISA}

Com vistas a contribuir para o objetivo do presente trabalho, foi realizada uma pesquisa exploratória, a fim de verificar se consumidoras de determinadas categorias 
de produtos adquirem (ou já adquiriram) algum bem de conveniência, considerando na totalidade ou parcialmente o "fator ecológico", e averiguar a predisposição em considerar tal fator nas suas decisões de compra. Se sim, admite-se que tal fator está presente na decisão de compra e que pode ser considerado uma ferramenta mercadológica à medida que atende a uma necessidade delas.

Dessa forma, foram elencados como objetivos específicos:

- Verificar se o consumidor observa quais matérias-primas são utilizadas na fabricação dos produtos que adquire e, se o faz, detectar se o fator ecológico está presente.

- Detectar qual a importância dada pelo consumidor à maneira como o produto que compra é fabricado, em função do dispêndio de recursos e do nível de poluição ao término do processo.

- Averiguar se o consumidor percebe se a embalagem dos produtos que compra pode ser nociva ao meio ambiente e se isso é levado em consideração na decisão de compra.

- Investigar quais características físicas do produto que o tornariam ecologicamente correto o consumidor alia ao meio ambiente e verificar quais dessas categorias estão presentes na decisão de compra.

- Indagar se o meio ambiente é fator de preocupação quando o consumidor descarta o produto.

As categorias definidas são consideradas pela teoria de marketing como bens de conveniência - aqueles comprados rápido e freqüentemente por consumidores que não promovem esforços para realizar a compra, não são muito leais às marcas disponíveis e avaliam como baixo o risco na tomada de decisão; essa categoria de bens não apresenta diferenças percebidas de qualidade e geralmente são vendidos por preço baixo e estão disponíveis em muitos pontos-de-venda (COBRA, 1997; KOTLER, 2000).

Fator ecológico, no contexto deste estudo, deve ser entendido como um atributo que torne o bem de conveniência o menos nocivo possível ao meio ambiente, à medida que não há produtos que em nada contribuam para a degradação ambiental (OTTMAN, 1994). Conforme relatam Wolf (apud OTTMAN, 1994), Ottman (1994), Jöhr (1994) e Schmidheiny (1992), tal fator está presente se o produto tiver características do tipo: fabricado com a quantidade mínima de matérias-primas e com matérias-primas renováveis, recicláveis e que conservem recursos naturais no processo de extração; fabricado com a máxima eficiência energética e de utilização de água e com o mínimo despejo de efluentes e resíduos; envasado em embalagens mais leves e mais volumosas; ser concentrado, mais durável, prestar-se a múltiplos 
propósitos, ser mais facilmente consertado, ter maior eficiência energética e conservar recursos naturais quando utilizado, ser reciclável, reutilizável e biodegradável, poder ser refabricado e ser substituído por refil.

O método de pesquisa empregado foi a entrevista focalizada de grupo, ou discussão de grupo, que serviu às exigências deste trabalho (e serve à pesquisa exploratória) já que se propôs a gerar hipóteses sobre opiniões, usos, costumes, valores, experiências, atitudes, estilos de vida, comportamentos passados e presentes e intenções, e não pretendeu-se utilizar os dados obtidos de forma conclusiva (BOYD; WESTFALL, 1987; MATTAR, 1997). A natureza das informações geradas é qualitativa, apropriada à pesquisa exploratória e, por conta disso, não houve a preocupação de quantificar resultados e generalizá-los a todo um universo (AAKER; KUMAR; DAY, 1998), mesmo porque o método da discussão de grupo não permite que os resultados sejam generalizados (CALDER, 1977).

As discussões foram realizadas em dezembro de 1999 e conduzidas de forma não estruturada, apesar de ter sido importante ao estudo promover, em primeiro plano, a discussão disfarçada, sem a citação explícita do fator ecológico, para posteriormente lançar ao debate caracterizações do fator ecológico e de sua influência no processo de decisão de compra. O disfarce da primeira etapa da discussão visou evitar possíveis vieses que o tema (meio ambiente) pudesse causar, já que a prática de consumo real dos entrevistados poderia ser distorcida face ao débito social que um possível desrespeito ao meio ambiente pudesse ocasionar. O método de disfarce utilizado foi a técnica projetiva da utilização da terceira pessoa, indicado por Aaker, Kumar e Day (1998), no escopo da pesquisa qualitativa, para as situações em que as pessoas são questionadas sobre algo que possa colocá-las em circunstâncias embaraçosas ou que impactem negativamente seus egos e status.

Foram realizadas duas discussões de grupo; mais discussões não foram realizadas por não acrescerem, usualmente, informações que não tenham sido geradas nas duas primeiras (AAKER; KUMAR; DAY, 1998). Estiveram presentes, em cada discussão, sete integrantes. Apesar de ser mais usual a realização de discussões de grupo com no mínimo oito e no máximo doze pessoas (média de dez integrantes), utilizou-se uma menor quantidade com o objetivo de estimular a participação ativa de todas as participantes (AAKER; KUMAR; DAY, 1998). Foi preocupação deste estudo que os integrantes absolutamente não se conhecessem anteriormente, com o objetivo de que suas opiniões não fossem afetadas por influências advindas de relacionamentos interpessoais (FERN, 1982). O perfil dos integrantes das discussões foi: sexo feminino, pois há uma preponderância desse sexo entre os consumidores mais ativos do ponto de vista ambiental (OTTMAN, 1994) e, além disso, este gênero é o responsável pela decisão de compra domiciliar de produtos de higiene e beleza e de limpeza (KARSAKLIAN, 2000); residentes na cidade de São Paulo, que concentra os melhores 
indicadores socioeconômicos e de posse de bens do país (ATLAS DO MERCADO BRASILEIRO, 1998), espelhando que as necessidades básicas da população estão satisfeitas e novas necessidades a serem satisfeitas (entre elas, a ambiental) possam emergir; participantes da decisão de compra de bens de conveniência, notadamente detergentes e cremes dentais; e idade entre 25 e 48 anos, pois segundo pesquisa realizada na região do ABC paulista (IMES, 1993), conurbada à cidade de São Paulo, essa faixa responde por $55 \%$ do consumo residencial mensal familiar.

A análise foi elaborada levando-se em consideração, primeiramente, que este estudo tem características exploratórias, e, conseqüentemente, antes de obter conclusões acerca da temática discutida, teve o intuito de gerar hipóteses e contribuir para ampliar o conhecimento na área que o trabalho enfoca. Num primeiro momento, a preocupação foi com a descrição pormenorizada das discussões de grupo, e a organização das informações reveladas pelas discussões considerou os tópicos do roteiro que serviu para conduzi-las. A descrição das opiniões das participantes das discussões precede as etapas posteriores (inclusive a de interpretação das opiniões) pelo fato de se constituir em um pré-requisito fundamental ao entendimento das interpretações e conclusões (PATTON, 1990); dessa forma, pode-se admitir que a análise do presente estudo iniciou-se durante a realização das discussões de grupo, ou imediatamente após sua conclusão, através do exame detalhado das notas taquigráficas e registros em áudio e vídeo; o início da etapa de análise de resultados concomitante à própria realização das discussões de grupo vai ao encontro da própria natureza da pesquisa qualitativa (PATTON, 1990). A fase de descrição do conteúdo das discussões de grupo foi intermediada pelas declarações textuais das participantes, que serviram de base às proposições do pesquisador. As declarações textuais, que tiveram origem no exame das notas taquigráficas e das fitas de áudio e vídeo, não passaram pelo crivo deste pesquisador, de forma a preservar a integridade das opiniões das participantes (WOLCOTT, 1994). A segunda etapa da análise revelou os achados obtidos nas discussões de grupo à luz dos objetivos específicos propostos, para que o objetivo principal seja automático e claramente respondido posteriormente, já que este é multifacetado, e cada faceta é representada por um objetivo específico. A terceira (e última) fase da análise foi reservada às conclusões que os achados permitiram que fossem obtidas e o ponto de referência, nesta etapa, sempre foi a resposta ao objetivo principal. Foi uma preocupação central, neste ponto, identificar os achados centrais obtidos no trabalho de campo e estabelecer inter-relações entre eles (WOLCOTT, 1994).

Por fim, é importante que se esclareça que os dois grupos de discussão foram analisados como se tivessem um só corpo, e não separadamente, pois a realização de dois grupos atendeu a uma premissa de esgotamento de opiniões inéditas sobre um mesmo tópico de discussão, e não à necessidade de estabelecimento de quotas demográficas, socioeconômicas ou psicográficas (AAKER; KUMAR; DAY, 1998). 


\section{RESULTADOS DA PESQUISA}

Realizadas as análises, conclui-se que as consumidoras residentes na cidade de São Paulo, com idades entre 25 e 48 anos e participantes da decisão de compra de bens de conveniência de uso doméstico não incluem o meio ambiente em seus processos de decisão de compra e que essa não inclusão é ocasionada, basicamente, pela falta de informação.

O público-alvo deste estudo não relaciona nenhum dos quatro determinantes da categorização de um produto ecologicamente correto (já listados acima) ao meio ambiente (ou à sua preservação).

A não inclusão do meio ambiente no processo de decisão de compra parece fazer impedir o lançamento de produtos ecologicamente corretos apenas por questões de marketing, no sentido restrito desta ciência, que procura angariar lucro satisfazendo às necessidades dos consumidores (KOTLER, 2000). Os consumidores ainda se encontram presos aos benefícios intrínsecos dos produtos e suas necessidades são satisfeitas se os produtos forem eficientes nestes quesitos, não importando se ele é capaz de degenerar o meio ambiente. Como o ser humano tende a perceber os estímulos que contribuem para a satisfação de suas necessidades (SCHIFFMAN; KANUK, 2000), mesmo os produtos ambientalmente corretos disponíveis no mercado brasileiro não são percebidos pelas consumidoras como detentores deste atributo "verde", pois a necessidade de preservar o meio ambiente não está presente.

Além disso, interessa aos consumidores solucionar seus problemas pessoais e não os do meio ambiente, imperando a conveniência e a praticidade que os produtos oferecem, o que é um dilema observado até entre os consumidores do hemisfério norte ambientalmente corretos, que relutam em abandonar seus estilos de vida (DUBOS, 1974; CAIRNCROSS, 1992; OTTMAN, 1994).

Dessa forma, seria necessário que o respeito ao meio ambiente e o imperativo de sua preservação estivessem atrelados às necessidades dos consumidores, ainda que de forma secundária, pois dificilmente viriam à frente da própria satisfação proporcionada pelo produto comprado (CAIRNCROSS, 1992), de modo que fosse gerada uma nova variável que os motivassem. Mais do que isso, seria desejável que os consumidores adquirissem auto-imagem "verde" e se vissem como elementos indispensáveis à preservação ambiental, pois isso os aproximaria dos produtos ecologicamente corretos e faria com que seus atributos ambientais fossem plenamente considerados nas decisões de compra (BENNETT; KASSARJIAN, 1975), o que mais uma vez mostra que é indispensável que tenham à disposição as informações necessárias (OTTMAN, 1994).

Porém, não há garantia de que a despreocupação atual dos consumidores com o meio ambiente seja perene e imutável, o que já é sinalizado pelas consumidoras que participaram das discussões em grupo: 
- a prática do consumo ambientalista em outros países é cada vez mais disseminada entre a sociedade brasileira, e a ecologia é encarada como algo que deveria ser motivo de maior preocupação;

- o consumo de produtos ecológicos proporciona maior qualidade de vida;

- os valores ecológicos devem ser transmitidos aos filhos, pois são corretos;

- confirmando as conclusões de Dinato et al. (1999), há conhecimento de muitas questões ambientais atuais, como biodegradabilidade de produtos, obrigações empresariais, problemas de disposição de lixo urbano, coleta seletiva de lixo, poluição atmosférica e de rios e mares e logomarca da reciclagem, a despeito da falta de informação;

- compraria-se produtos "verdes", confirmando os achados de Dinato et al. (1999);

- deseja-se coleta seletiva de lixo;

- há preferência por detergentes biodegradáveis;

- evita-se aerossóis, o que é característico do comportamento dos "verdes" verdadeiros, categoria à qual pertencem os que crêem na existência dos problemas ambientais e que são duas vezes mais propensos a comprarem produtos "verdes" (OTTMAN, 1994); e

- pagaria-se mais por produtos ambientalmente corretos, demonstrando uma ampliação da qualidade do produto, confirmando a pesquisa apresentada por Ottman (1994).

Seria necessário, entretanto, para que fosse criada (ou aprimorada) uma consciência ambiental na grande massa dos consumidores, que a iniciativa partisse principalmente do poder público, conforme as próprias consumidoras que participaram das discussões afirmaram. A responsabilidade da empresa recairia em informar corretamente as características dos produtos que os tornem "verdes" e, principalmente, atestar a completa veracidade das informações transmitidas.

De qualquer maneira, para que seja elevada a consciência ambiental dos consumidores e para que ela seja transportada para as decisões de consumo, é importante que tanto a depleção ambiental quanto as alternativas à disposição para combatê-la sejam "percebidas", a ponto de serem integradas à estrutura cognitiva dos consumidores e ao rol das necessidades a serem satisfeitas; diante disso, estímulos "verdes" proporcionados pela empresa - como produtos, embalagens, propaganda, relações públicas - (SCHIFFMAN; KANUK, 2000) constituem-se em esforços vitais para que futuramente se colha vantagens competitivas.

Os consumidores isentam-se da responsabilidade de preservar o meio ambiente, alegando, por exemplo, que não reúnem informações necessárias para discernirem entre produtos ecologicamente corretos e produtos "normais", conforme já fora 
evidenciado por Ottman (1994). Além disso, promovem uma auto-resistência em adquirirem um comportamento que não condiga com o da maioria, e embarcariam em novos hábitos e atitudes a partir do momento que não se sentissem excluídos.

Particularmente em relação às atitudes, observa-se que elas são positivas em relação ao meio ambiente, ou seja, os consumidores concordam que ele está sendo degradado e que algo deve ser feito para que tal fenômeno seja freado; porém, essas atitudes positivas não se transformam, efetivamente, em comportamento, e muito menos em comportamento de compra, o que já fora explanado por Zimbardo e Ebbesen (1973), e confirmado por Hini, Gendall e Kearns (1995). Os motivos mais evidentes são a carência de informação e de oferta para tal e o fato do meio cultural e social em que vivem - sobretudo seus grupos de referência - não imprimir a noção de que todos são parte dos problemas ambientais e que, conseqüentemente, devem fazer parte da solução. A importância de se preservar o meio ambiente, portanto, é considerada pelos consumidores, mas, por conformidade com as regras sociais impostas por instituições e grupos de referência (SOLOMON, 1996), não é transportada às decisões de consumo. A desaprovação ao comportamento afinado ao meio ambiente (inclusive o de compra) dos grupos de referência apontada por algumas consumidoras participantes das discussões funciona como um reforço negativo (ENGEL; BLACKWELL; MINIARD, 1995) na ocorrência da incidência do comportamento sobre o ambiente (SKINNER, 1998).

\section{CONSIDERAÇÕES FINAIS}

Muito embora a pesquisa realizada tenha sido exploratória e, portanto, não permita a generalização dos resultados dela provenientes, diversas considerações foram tecidas, com o intuito de contribuir para a evolução do assunto abordado neste artigo.

$\mathrm{Na}$ ocasião da realização da pesquisa, o fator ecológico não era levado em consideração nas decisões de compra de bens de conveniência de higiene pessoal pelas consumidoras que participaram dos grupos de foco. No entanto, chama a atenção o que se considerou ser uma predisposição para a compra de produtos ecologicamente corretos, uma vez que se verificaram atitudes positivas em relação ao meio ambiente.

Dessa forma, a carência de informações relativas ao assunto coloca-se como uma barreira para que ações sejam empreendidas pelos consumidores, em prol do meio ambiente, por meio da compra de produtos ecologicamente corretos.

Relacionando-se os achados da pesquisa de campo com a teoria da vantagem competitiva apresentada no item II do presente artigo, pode-se entender que: 
- Como a variável ambiental ainda não está presente nas decisões de compra dos consumidores, a função de marketing das empresas interessadas em angariar vantagem competitiva não (ou pouco) considera o fator ambiental nas suas decisões, pois não é evidente para elas que os produtos "verdes" criam valor para os consumidores;

- A falta de comportamento de compra favorável a produtos ambientalmente corretos induz as empresas a acreditarem que o timing para a utilização dessa variável para definir parte das suas estratégias de marketing ainda está por vir;

- Se a preocupação com o meio ambiente inserir-se no processo de decisão de compra dos consumidores, as ações de marketing ecológico podem ser um elemento de criação de valor e, conseqüentemente, de vantagem competitiva baseada em diferenciação; no entanto, a já verificada não transposição das atitudes favoráveis à preservação ambiental ao comportamento de compra impede, pelo menos por hora, a adoção da estratégia de diferenciação baseada nesta variável;

- Como foi identificada uma predisposição dos consumidores de pagarem um preço-prêmio por produtos "verdes", demonstrando claramente que se atribui maior valor a esses produtos, a vantagem competitiva pode ser criada sobre a diferenciação;

- Como o motivo principal da desconsideração do meio ambiente no momento da compra é a falta de informação, ações de comunicação da empresa (nitidamente presentes no escopo de marketing) podem instruir sobre as vantagens (e diferenciais competitivos) dos produtos (e de posturas) ambientalmente corretos;

- O escopo do marketing ecológico é, nitidamente, mais afeito à criação de vantagem competitiva baseada em diferenciação (com ou sem enfoque), pois os custos de implantação de suas ações são maiores, bem como porque amplia o valor ofertado aos consumidores; de fato, como foi demonstrado por Narver e Slater (1990), há uma correlação maior entre a estratégia de diferenciação e a orientação para o mercado das empresas (e as conseqüentes ações táticas de marketing que essa orientação gera) do que entre a estratégia de liderança em custo e a orientação para o mercado;

- Outras práticas de gestão ambiental, como controle de resíduos e efluentes, diminuição de quantidade de matéria-prima utilizada na fabricação, menor consumo de água e energia nas operações, etc., reduzem custos e podem levar a empresa a adotar uma estratégia de liderança em custo, à medida que o know how para isso seja barateado e amplamente disponível;

- Em função da falta de um mercado "verde" consolidado, já que os consumidores apenas manifestam intenções de aquisição de produtos ecologica- 
mente corretos, a estratégia de foco, destinada ao segmento de atitude mais comprovada em relação ao consumo de produtos "verdes", pode, hoje, ser a mais viável no Brasil; e

- A empresa que não se voltar à atitude favorável dos consumidores em relação às questões ambientais pode deixar de obter vantagem competitiva, dentro da "hipercompetição" defendida por D'Aveni (1995), se essas atitudes forem refletidas em comportamento de compra.

Por fim, vale ressaltar que embora haja necessidade de relativo esforço no aculturamento da sociedade acerca da relevância e dos benefícios advindos de práticas empresariais responsáveis ambientalmente, essa arena competitiva coloca-se como um oásis em meio a um deserto cercado por práticas concorrenciais degenerativas e o clamor da sociedade - que ocorre, ainda, de maneira um tanto silenciosa, mas que ganha força dia a dia.

\section{REFERÊNCIAS}

AAKER, David A.; KUMAR, V.; DAY, George S. Marketing research. New York: John Wiley \& Sons, 1998.

ATLAS DO MERCADO BRASILEIRO. São Paulo: Gazeta Mercantil, 1998-Anual.

BENNETT, Peter D.; KASSARJIAN, Harold H. O comportamento do consumidor. São Paulo, Atlas, 1975.

BOYD. Harper W.; WESTFALL, Ralph. Pesquisa mercadológica: textos e casos. Rio de Janeiro: Editora da Fundação Getulio Vargas, 1987.

CAIRNCROSS, Frances. Meio ambiente: custos e benefícios. São Paulo: Nobel, 1992.

CALDER, Bobby J. Focus group and the nature of qualitative marketing research. Journal of Marketing Research, Chicago, v. XIV, n. 3, p. 353-364, ago. 1977.

CALOMARDE, José V. Marketing ecológico. Madrid: Pirâmide, ESIC, 2000.

CHURCHILL, Jr.; GILBERT A.; PETER, J. Paul. Marketing: criando valor para os clientes. São Paulo: Saraiva, 2000.

COBRA, Marcos H. N. Marketing básico: uma abordagem brasileira. São Paulo: Atlas, 1997. 
Competitividade baseada no marketing ecológico

D’AVENI, Richard A. Hipercompetição: estratégias para dominar a dinâmica do mercado. Rio de Janeiro: Campus, 1995.

DINATO, Monique Revillion et al. O comportamento ambiental do consumidor de Porto Alegre. In: Encontro Nacional sobre Gestão Empresarial e Meio Ambiente. 5, 1999. Anais.... São Paulo. p. 619-631.

DUBOS, René. Um animal tão humano: como somos moldados pelo ambiente e pelos acontecimentos. São Paulo: Melhoramentos, Editora da Universidade de São Paulo, 1974.

EL-ANSARY, Adel I. Towards a definition of social and societal marketing. Academy of Marketing Science, Greenvale, v. 2, n. 2, primavera de 1974.

ENGEL, James F.; Blackwell, Roger D.; MINIARD, Paul W. Consumer behavior. Orlando: The Dryden Press, 1995.

FERN, Edward F. The use of focus group for idea generation: the effects of group size, acquaintanceship, and moderator on response quantity and quality. Journal of Marketing Research, Chicago, v. XIX, n. 1, p. 1-13, fev. 1982.

GRACIOSO, Francisco. Marketing: uma experiência brasileira. São Paulo, Cultrix, s.d.

HINI, Dean, Gendall, Philip, Kearns, Zane. The link between environmental attitudes and behavior. Marketing Bulletin, Palmerston North, v. 6, p. 22-31, 1995.

INSTITUTO MUNICIPAL DE ENSINO SUPERIOR DE SÃO CAETANO DO SUL. Relatório do $1^{\circ}$ levantamento: pesquisa sócio-econômica do ABC. São Caetano do Sul: INPES, 1992. Anual.

JÖHR, Hans. O verde é negócio. São Paulo: Saraiva, 1994.

KARSAKLIAN, Eliane. Comportamento do consumidor. São Paulo: Atlas, 2000.

KINLAW, Dennis C. Empresa competitiva e ecológica. São Paulo: Makron Books, 1998.

KOTLER, Philip. Administração de marketing: a edição do novo milênio. São Paulo: Prentice-Hall, 2000. 
LAS CASAS, Alexandre L. Marketing: conceitos, exercícios, casos. São Paulo: Atlas, 1997.

LAYRARGUES, Philippe P. A cortina de fumaça: o discurso empresarial verde e a deologia da racionalidade econômica. São Paulo: Annablume, 1998.

LEVITT, Theodore. Marketing para desenvolvimento dos negócios. São Paulo: Cultrix, s.d.

MATTAR, Fauze N. Pesquisa de marketing: metodologia, planejamento. São Paulo: Atlas, 1997.

McCARTHY, E. Jerome. Basic marketing approach. Homework: Irwin, 1960.

McCARTHY, E. Jerome, Perreault Jr., William D. Marketing essencial: uma abordagem gerencial e global. São Paulo: Atlas, 1997.

MILES, Morgan, Munilla, Linda S. The eco-marketing orientation: an emerging business philosophy. In: POLONSKY, Michael J., Mintu-Wimsatt, Alma T. (Edit.). Environmental marketing: strategies, practice, theory, and research. Nova Iorque: Haworth, 1995.

MOTTA, Sérgio Luís Stirbolov. A influência do fator ecológico na decisão de compra de bens de conveniência. Dissertação (Mestrado em ??) - Faculdade de Ciências Econômicas, Contábeis e Administrativas. São Paulo: Universidade Mackenzie, 2000.

NARVER, John C.; Slater, Stanley F. The effect of a market orientation on a business profitability. Journal of Marketing, Nova Iorque, outubro de 1990.

OTTMAN, Jacquelyn A. Marketing verde: desafios e oportunidades para a nova era do marketing. São Paulo: Makron Books, 1994.

PATTON, Michael Q. Qualitative evaluation and research methods. Sage: Newbury Park: 1990.

PORTER, Michael E. Estratégia competitiva: técnicas para análise de indústrias e da concorrência. Rio de Janeiro: Campus, 1986.

RICHERS, Raimar. O que é marketing. São Paulo: Brasiliense, 1994. 
ROCHA, Angela da; CHRISTENSEN, Carl. Marketing: teoria e prática no Brasil. São Paulo: Atlas, 1999.

SCHIFFMAN, Leon G.; KANUK, Leslie L. Comportamento do consumidor. Rio de Janeiro: LTC, 2000.

SCHMIDHEINY, Stephan. Mudando o rumo: uma perspectiva empresarial global sobre desenvolvimento e meio ambiente. Rio de Janeiro: Editora da Fundação Getulio Vargas, 1992.

SEMENIK, Richard J.; BAMOSSY, Gary J. Princípios de marketing: uma perspectiva global. São Paulo: Makron Books, 1995.

SHETH, Jagdish N.; GARDNER, David M. History of marketing though: an update. In: BROWN, Stephen W.; FISK, Raymond P. (Edit.). Marketing theory: distinguished contributions. Nova Iorque: John Wiley \& Sons, 1984.

SILVA, Adriano. Que diabo é isso? Revista Exame, São Paulo, p. 76-83, jul. 1997.

SKINNER, Burrhus F. Ciência e comportamento humano. São Paulo: Martins Fontes, 1998.

SOLOMON, Michael R. Consumer behavior: buying, having and being. New Jersey: Prentice-Hall, 1996.

WOLCOTT, Harry F. Transforming qualitative data: description, analysis, and interpretation. Thousand Oaks: Sage: 1994.

ZIMBARDO, Philip G.; EBBESEN, Ebbe B. Influência em atitudes e modificação de comportamento. São Paulo: EDUSP, 1973. 